\title{
Temperature-sensitive Tyrosinase Associated with Peripheral Pigmentation in Oculocutaneous Albinism
}

\author{
Richard A. King, "*1 DeWayne Townsend,* William Oetting," C. Gail Summers, \\ David P. Olds," James G. White," and Richard A. Spritz** \\ Departments of *Medicine, ${ }^{\ddagger}$ Ophthalmology, ${ }^{\S}$ Pediatrics, and "Laboratory Medicine and Pathology, and the "Institute of Human \\ Genetics, University of Minnesota, Minneapolis, Minnesota 55455; and the Departments of **Medical Genetics \\ and Pediatrics, University of Wisconsin-Madison, Madison, Wisconsin 53706
}

\begin{abstract}
Several types of autosomal recessive oculocutaneous albinism (OCA) are associated with abnormal tyrosinase function and a generalized reduction in or absence of cutaneous and eye melanin. Each is thought to result from a different mutant allele at the tyrosinase locus, with the mutation producing an enzyme with little or no activity in all involved tissues. In this paper, we report a new type of OCA that results from a tyrosinase allele producing a temperature-sensitive enzyme. The proband had white hair in the warmer areas (scalp and axilla) and progressively darker hair in the cooler areas (extremities) of her body. Melanocyte and melanosome architecture were normal. Quantitative hairbulb tyrosinase (dopa oxidase) assay demonstrated a loss of activity above $35-37^{\circ} \mathrm{C}$. Plasma pheomelanin and urine eumelanin intermediates were reduced and correlated with hair melanin content. This is the first temperature-sensitive tyrosinase mutation to be reported in humans and is analogous to the Siamese mutation in the cat and the Himalayan mutation in the mouse. (J. Clin. Invest. 1991. 87:1046-1053.) Key words: enzyme $\bullet$ mutation $\bullet$ melanin $\bullet$ gene $\bullet$ pigment $\bullet$ albinism
\end{abstract}

\section{Introduction}

Tyrosinase controls the initial steps of the melanin pathway, and altered function of this enzyme is thought to be responsible for several types of human oculocutaneous albinism (OCA). ${ }^{1}$ Type IA (tyrosinase negative) OCA is associated with a total absence of tyrosinase function and melanin synthesis in the skin, hair follicles, and the eye (1). Type IB (yellow) OCA also has diminished tyrosinase function yet the associated phenotype has an absence of skin, hair, and eye melanin only at birth followed by the development of scalp hair pheomelanin and subsequent eumelanin with time $(1,2)$. Type IA and IB OCA

This work was reported in abstract form at American Society of Human Genetics, November 1989.

Address reprint requests to Richard A. King, M.D., Ph.D., Box 485 UMHC, University of Minnesota, Harvard Street at East River Road, Minneapolis, MN 55455.

Received for publication 25 April 1990 and in revised form 21 September 1990.

1. Abbreviations used in this paper: OCA, oculocutaneous albinism; TMH-1, a monoclonal antibody to tyrosinase.

J. Clin. Invest.

(C) The American Society for Clinical Investigation, Inc. 0021-9738/91/03/1046/08 \$2.00

Volume 87, March 1991, 1046-1053 are allelic, and represent different mutations at a single locus (3). Type III (minimal pigment) OCA, is also thought to result from altered tyrosinase function, and individuals with this type of OCA may be genetic compounds with two different abnormal tyrosinase alleles $(4,5)$. It has been proposed that the genes responsible for these types of OCA may form an allelic series similar to that of the $c$-locus in the mouse (5).

We now present a new type of OCA that appears to result from another tyrosinase allele. Affected individuals have no pigment in the scalp and axillary hair, light pigment in the body and pubic hair, and dark pigment in the hair of the extremities. This unusual pigment pattern suggested that this type of OCA resulted from a tyrosinase mutation producing a temperaturesensitive enzyme. This was documented by the analysis of hairbulb tyrosinase activity.

Case report. The family pedigree is presented in Fig. 1; this is part of a large pedigree containing individuals with type IA OCA in other branches, to be described elsewhere. The proband, individual II-4, was $18 \mathrm{yr}$ of age when evaluated in the Clinical Research Center at the University of Minnesota. At birth, she had white hair and skin, and blue eyes, and the diagnosis of oculocutaneous albinism was made in the first week of life. Nystagmus and photophobia were present, and she began to wear glasses at 4-5 yr of age because of reduced visual acuity. Her acuity was 20/300 without correction and 20/200 with spectacles. There was little change in her pigmentation until puberty at which time she developed darker hair on her legs. She subsequently noted that her axillary hair remained "dead white" and her scalp hair developed a slight yellow tint (which she related to the use of shampoos). Her arm hair became light reddish-tan, and her pubic hair varied in color from yellow to light tan. Her skin remained white but she felt that a slight tan developed after prolonged sun exposure, and she developed multiple pigmented nevi on her trunk and extremities. Her health had been good and there were no bleeding problems. She was a high school graduate.

Samples of hair from different body locations are shown in Fig. 2. Her scalp hair was white with a slight yellow tint, particularly towards the ends of the hair strands. The hair closer to the scalp had less of a yellow tint. Eyebrow hair was reddish-blond. Eyelash hair was yellow. Axillary hair was white with no evidence of pigment. Forearm hair was reddish blond. Pubic hair was generally dark yellow with areas of light brown color. Lower leg hair was dark brown.

Skin color was creamy white and there appeared to be some increase in color over the exposed surfaces of the arms and the upper posterior trunk. Scattered melanotic nevi were present on the trunk and proximal extremities, and dark hair was growing from many. With correction for mild hyperopia and a 
II

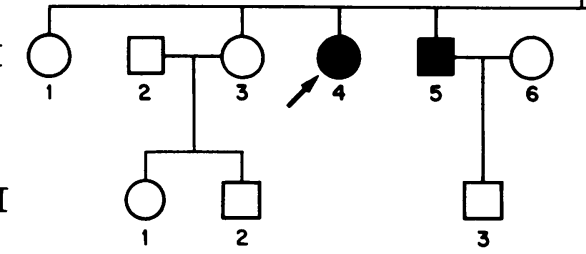

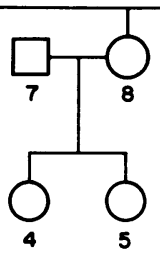

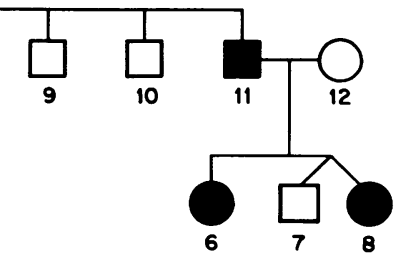

Figure 1. Family pedigree. The proband is individual II-4. Solid symbols represent OCA. marked amount of astigmatism, binocular and monocular visual acuity was recorded at 20/200; near acuity was Jaeger 12 14 print at 5 in. Variable pendular nystagmus with a compensatory left head turn was noted, and motility evaluation showed moderate deficiency of elevation of each eye and a 35 prism diopter esotropia. Slit lamp examination of the anterior segment was significant for full transillumination of the blue irides. Fundiscopic examination showed foveal hypoplasia, absence of visible melanin pigment, and visualization of the choroidal vessels in both the macula and peripheral fundus.

The proband's affected siblings (individuals II-5 and II-11 in the pedigree) had an identical phenotype, with white scalp and axillary hair, and pigmented arm and leg hair after puberty. Two of the offspring of individual II-11 had OCA but both were prepubescent and had only white hair. There was no known consanguinity between individuals II-11 and II-12, and the presence of OCA in their offspring was assumed to repre- sent pseudodominance with individual II-12 being an unrelated heterozygote for an abnormal tyrosinase allele. No biochemical studies were performed on individuals II-5, II-11, II12 , III- 6 , or III-8, and they were unavailable for evaluation in the Clinical Research Center at the University of Minnesota.

\section{Methods}

Hairbulb melanocyte tyrosinase activity. Tyrosine hydroxylase activity of tyrosinase was determined with enzyme extracted from 10 fresh anagen hairbulbs, using a tritiated tyrosine assay (1). Hairbulbs were incubated on ice in $0.2 \mathrm{ml}$ of $0.1 \mathrm{M} \mathrm{NaPO}_{4}$ buffer, $\mathrm{pH} 6.8$, containing $0.5 \%$ Triton $\mathrm{X}-100$ for $60 \mathrm{~min}$ and the supernatant used as the enzyme extract. The reaction mixture contained $0.2 \mu \mathrm{M}$ L-tyrosine- $3,5-{ }^{3} \mathrm{H}$ ( 2 or $50 \mathrm{Ci} / \mathrm{mmol}$ ) and $0.1 \mu \mathrm{M} \mathrm{L}$-dopa in $0.1 \mathrm{M} \mathrm{NaPO}_{4}$ buffer, $\mathrm{pH} 6.8$, and $20 \mu \mathrm{l}$ of the enzyme extract in a total volume of $60 \mu$ l. The reaction mixture was incubated at $37^{\circ} \mathrm{C}$ (standard) or at different temperatures as indicated in the text. At 0,60 , and $120 \mathrm{~min}$, a $10-\mu \mathrm{l}$ aliquot was

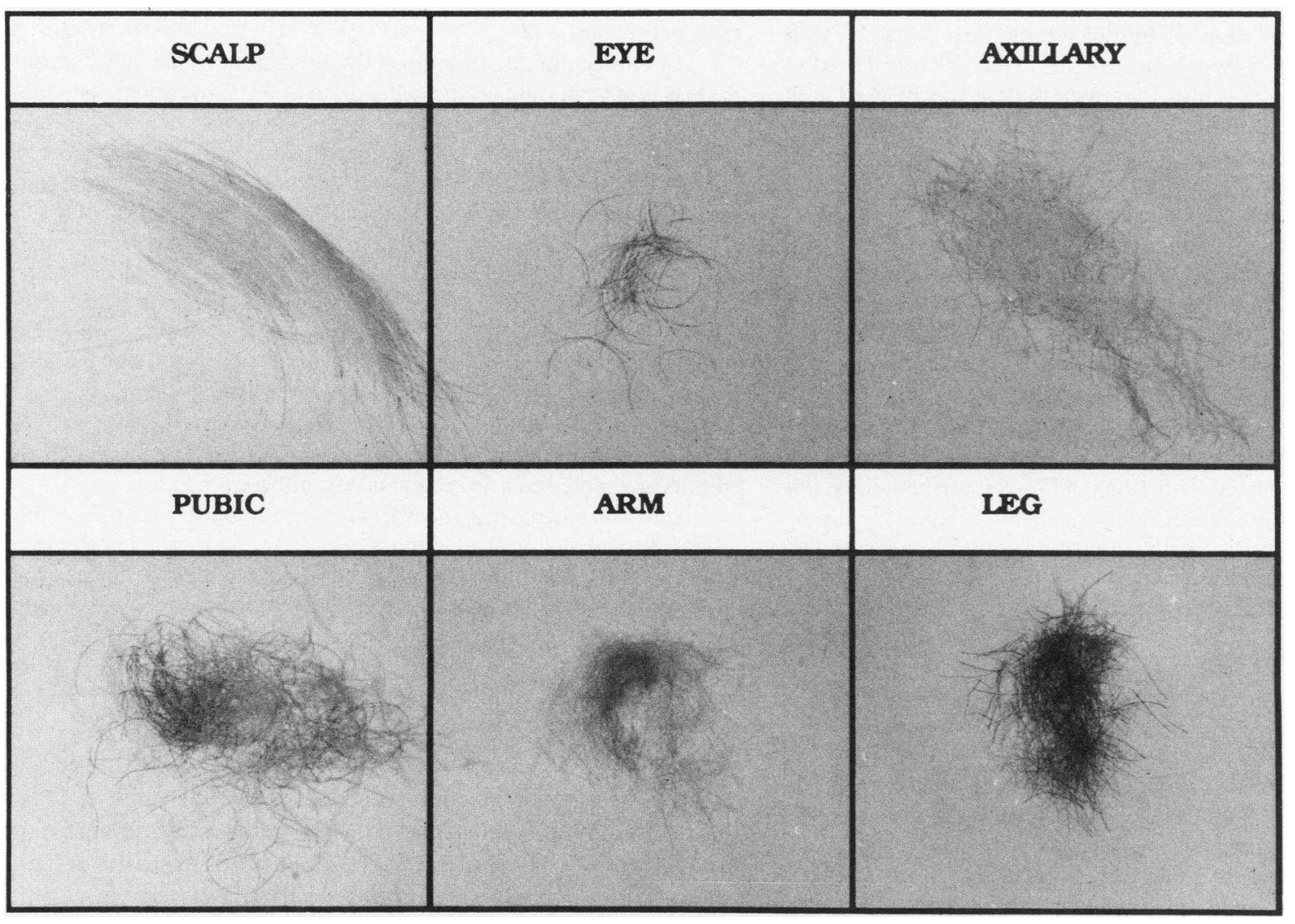

Figure 2. Hair samples from individual II-4. The eye sample is from the eyebrows. 
placed on a small Dowex $50 \mathrm{~W}$ column and the ${ }^{3} \mathrm{HOH}$ generated by the oxidation of tyrosine was recovered with a citrate wash. Enzyme activity was expressed in picomoles of tyrosine oxidized per hairbulb per hour. Scalp and leg anagen hairbulbs were used for the assays.

Dopa oxidase activity of tyrosinase was determined with enzyme extracted from three fresh anagen hairbulbs, using an HPLC assay (6). Duplicate sets of three hairbulbs were washed in PBS and the enzyme extracted with $0.5 \%$ Triton $\mathrm{X}-100$ in $10 \mathrm{mM} \mathrm{NaPO}_{4}$ buffer, pH 6.8. The reaction mixture contained $8 \mu \mathrm{M} \mathrm{L}$-cysteine, $29.3 \mu \mathrm{M} \mathrm{L}$-dopa, and $23 \mathrm{mM} \mathrm{NaCl}$ in $10 \mathrm{mM} \mathrm{NaPO}_{4}$ buffer, $\mathrm{pH} 6.8$, with $0.1 \%$ Triton X-100 in a total volume of $30 \mu \mathrm{l}$. The assay mixtures were incubated at $37^{\circ} \mathrm{C}$, or as indicated in the text, for $30 \mathrm{~min}$. The reactions were stopped with $10 \mu \mathrm{l}$ of cold $0.4 \mathrm{~N} \mathrm{HClO}_{4}$ containing $0.2 \mu \mathrm{g}$ 5-S-D-cysteinyldopa as an internal standard, and cooled on ice for $5 \mathrm{~min}$. The solution was centrifuged to pellet the protein precipitate and $20 \mu \mathrm{l}$ of the supernatant was analyzed by HPLC. The HPLC separation was performed using a C-18 silica (ODS2) column, and a mobile phase containing $30 \mathrm{mM}$ phosphoric acid, $64 \mathrm{mM}$ methanesulfonic acid, $0.1 \mathrm{mM}$ EDTA, 0.8\% methanol, pH 3.0, at a flow rate of $1.5 \mathrm{ml} / \mathrm{min}$. The $5-S$-cysteinyldopa (5SCD) and the 2-S-cysteinyldopa ( $2 S C D$ ) products of the reaction were detected electrochemically and quantitated by comparison with authentic standards. Enzyme activity was expressed as pmoles per hairbulb per hour.

Immunologic detection of tyrosinase polypeptides. The presence of material in hairbulbs that would react with a monoclonal antibody to tyrosinase (TMH-1; reference 7) was determined by immunoblotting (8). 50 hairbulbs were washed with $62.5 \mathrm{mM}$ Tris(hydroxymethyl)aminomethane hydrochloride (Tris) buffer, $\mathrm{pH} 6.8$, and then extracted by mild sonication at room temperature in $100 \mu \mathrm{l}$ of $62.5 \mathrm{mM}$ Tris containing $1 \%$ Triton X-100 and 2.5\% SDS without mercaptoethanol. The extract was filtered, applied to a $7.5 \%$ acrylamide SDS gel, and electrophoresed at $15 \mathrm{~mA}$ constant current. The samples were applied in triplicate to three sections of the gel. One section was stained with Coomassie G-250 to indicate total protein; the second was treated for 10 min with $10 \mathrm{mM} \mathrm{NaPO}_{4}$ buffer, $\mathrm{pH} 6.8$ at $0^{\circ} \mathrm{C}$ and then was incubated in $4 \mathrm{mM}$ dopa in $10 \mathrm{mM}$ phosphate buffer, pH 6.8 at $37^{\circ} \mathrm{C}$ to determine the location of tyrosinase; the third lane was transferred to nitrocellulose by electroblotting. The nitrocellulose was blocked with 3\% gelatin (Bio-Rad Laboratories, Richmond, CA) for $2 \mathrm{~h}$, washed in Tris-buffered saline containing $0.05 \%$ Tween 20 (TTBS), incubated with the TMH-1 antibody (7) at 1:500 dilution overnight, washed with TTBS, incubated with rabbit anti-rat IgG antibody (Cappel Laboratories, Inc., Cochranville, PA) at 1:800 dilution for $1 \mathrm{~h}$, washed with TTBS, incubated with alkaline phosphatase-conjugated goat anti-rabbit IgG antibody (Bio-Rad Laboratories) at 1:3,000 dilution for $1 \mathrm{~h}$, washed with TTBS and Tris buffered saline, and incubated with the color development solution (5-bromo-4-chloro-3-indoly phosphate toluidine salt/nitro blue tetrazolium chloride) for $1-4 \mathrm{~h}$.

Melanin pathway intermediates. Plasma SSCD was quantitated by reverse-phase HPLC with electrochemical detection $(9,10)$. A 4-ml sample of plasma was mixed with $10 \mathrm{ng}$ of 5-S-D-cysteine-L-dopa (internal standard) and $100 \mathrm{mg}$ aluminum oxide for $15 \mathrm{~min}$. The aluminum oxide was then washed with water, transferred to a microfilter apparatus, and the water was removed by centrifugation. The cysteinyldopas were released from the aluminum oxide by treating the filter with $0.4 \mathrm{ml}$ of $1 \mathrm{~N}$ perchloric acid for $10 \mathrm{~min}$, followed by centrifugation. The 0.4-ml filtrate was then injected directly into the HPLC. The sample was analyzed on a $\mathrm{C}-18$ reverse-phase column using a mobile phase containing $30 \mathrm{mM} \mathrm{H}_{3} \mathrm{PO}_{4}, 42 \mathrm{mM}$ methanesulfonic acid, 0.1 $\mathrm{mM}$ EDTA, and $0.8 \%$ methanol, $\mathrm{pH} 2.79$, run at $1.5 \mathrm{ml} / \mathrm{min}$. The electrochemical detector was set at $650 \mathrm{mV}$ vs. $\mathrm{Ag} / \mathrm{AgCl}$ with $20 \mathrm{nA}$ sensitivity. The amount of SSCD was determined by comparison with the standard curve for the 5-S-L-cysteine-D-dopa. The results are expressed as nanograms per milliliter of plasma.

Urine 5-methoxy-6-hydroxyindole-2-carboxylic acid (5M6HICA) was quantitated by HPLC with fluorescent detection $(11,12)$. A 24-h urine sample was collected on ice. A 4.0-ml aliquot was adjusted to $\mathrm{pH}$
6.0-6.5 and mixed with $1 \mu \mathrm{g}$ of 5-methoxyindole-2-carboxylic acid (internal standard), $0.5 \mathrm{ml}$ of $1.25 \mathrm{M}$ sodium acetate, $\mathrm{pH} \mathrm{6.2,} \mathrm{and} 0.1$ $\mathrm{ml}$ Helix pomatia juice (Sigma S-9751; contains $\beta$-glucuronidase). The mixture was bubbled with $\mathrm{N}_{2}$ for $30 \mathrm{~s}$ and incubated in a shaking waterbath at $37^{\circ} \mathrm{C}$ for $90 \mathrm{~min}$. The sample was then saturated with $\mathrm{NaCl}$, bubbled with $\mathrm{N}_{2}$ for $30 \mathrm{~s}$, and extracted twice with $4.0 \mathrm{ml}$ of diethylether. The extract was evaporated with $\mathrm{N}_{2}$, redissolved in $0.5 \mathrm{ml}$ of mobile phase, and $20 \mu \mathrm{l}$ was injected into the HPLC. The sample was analyzed on a C-18 reverse-phase column with a $15-40 \%$ methanol gradient; the mobile phase contained $0.05 \mathrm{M}$ sodium acetate, $0.1 \mathrm{mM}$

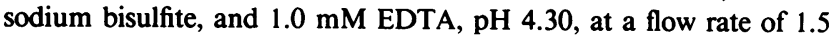
$\mathrm{ml} / \mathrm{min}$. The fluorometer was set at an excitation of $308 \mathrm{nM}$ and an emission of $395 \mathrm{nM}$. The amount of 5M6HICA was determined by comparison to a standard curve for 5M6HICA. The results are expressed as nanograms per milligram creatinine.

Hair melanin. Hair eumelanin and pheomelanin were quantitated by the method of Ito (13). A 10-mg sample of hair was homogenized in $1.0 \mathrm{ml}$ of $\mathrm{H}_{2} \mathrm{O}$ in a ground glass homogenizer until the hair was a uniform homogenate. For pheomelanin quantitation, $0.4 \mathrm{ml}$ of the homogenate was first dried overnight at $37^{\circ} \mathrm{C}$, then washed with $0.4 \mathrm{ml}$ of $50 \% \mathrm{H}_{3} \mathrm{PO}_{4}$, sonicated for $1-2 \mathrm{~h}$, stirred, and centrifuged in a small tube. The supernatant was removed and the tube was placed in an evacuation vial, to which was added $200 \mu \mathrm{l}$ of $57 \%$ solution of HI. The vial was flushed with argon or helium gas, evacuated, and placed in a sandbath at $130^{\circ} \mathrm{C}$ overnight. The vial was cooled and the HI was removed from the outside of the tubes. The tubes were lyophilized overnight to remove excess $\mathrm{HI}$. The residue was then transferred from the tube with two $500-\mu \mathrm{l}$ washes of $0.4 \mathrm{M} \mathrm{HClO}_{4}$, and a $20-\mu \mathrm{l}$ aliquot analyzed by HPLC with electrochemical detection. The 3-aminotyrosine (3AT) product of pheomelanin oxidation was analyzed on a C-18 column with a mobile phase containing $30 \mathrm{mM} \mathrm{H}_{3} \mathrm{PO}_{4}, 42 \mathrm{mM}$ methanesulfonic acid, and $0.1 \mathrm{mM}$ EDTA, $\mathrm{pH} 2.30$, at a flow rate of 1.5 $\mathrm{ml} / \mathrm{min}$. The electrochemical detector was set at $400 \mathrm{mV}$ vs. $\mathrm{Ag} / \mathrm{AgCl}$ with $20 \mathrm{nA}$ sensitivity. The amount of $3 \mathrm{AT}$ was determined by comparison to a standard curve, and the results are expressed as nanograms per milligram hair.

For eumelanin quantitation, a $0.4-\mathrm{ml}$ aliquot of the hair homogenate was centrifuged and the pellet dried at $37^{\circ} \mathrm{C}$ overnight. The sample was then mixed with $1.0 \mathrm{ml}$ of $1 \mathrm{M} \mathrm{H}_{2} \mathrm{SO}_{4}$, sonicated until homogeneous, and oxidized with permanganate by the addition of $20 \mu \mathrm{l}$ of $3 \%$ $\mathrm{KMnO}_{4}$ followed by an additional $20 \mu \mathrm{l}$ when the original purple color fades. The reaction was stopped after $10 \mathrm{~min}$ by the addition of $0.1 \mathrm{ml}$ of $10 \% \mathrm{Na}_{2} \mathrm{SO}_{4}$. The sample was extracted with ether and then evaporated with $\mathrm{N}_{2}$. The residue was dissolved in $0.2 \mathrm{ml}$ of $95 \%$ ethanol and a 20- $\mu$ aliquot analyzed by HPLC with ultraviolet detection at $254 \mathrm{~nm}$ at 0.001 AUFS. The pyrrole-2,3,5-tricarboxylic acid (PTCA) product of the eumelanin oxidation was analyzed on a $C-18$ column with a mobile phase containing $30 \mathrm{mM} \mathrm{H}_{3} \mathrm{PO}_{4}, 42 \mathrm{mM}$ methanesulfonic acid, 0.1 $\mathrm{mM}$ EDTA, $0.8 \%$ methanol, $\mathrm{pH} 2.79$, at a flow rate of $1.5 \mathrm{ml} / \mathrm{min}$. The PTCA was quantitated by comparison with a standard curve, and the results are expressed as nanograms per milligram hair.

Hairbulb melanocyte ultrastructure. Fresh anagen scalp hairbulbs were preincubated in $0.1 \%$ glutaraldehyde for $60 \mathrm{~min}$, incubated in 4 $\mathrm{mM}$ L-dopa for $90 \mathrm{~min}$, and fixed in 3\% glutaraldehyde for electron microscopy. Fresh anagen leg hairbulbs were fixed directly in $3 \%$ glutaraldehyde.

\section{Results}

Immunoblot of hairbulb tyrosinase. The proband (individual II-4 in Fig. 1) had an unusual OCA phenotype that included white scalp and axillary hair, reddish brown arm hair, and dark brown leg hair. This indicated that the amount or the activity of tyrosinase varied by location in a pattern that correlated with regional body temperature. Immunoblot assay of tyrosinase, using an anti-tyrosinase monoclonal antibody (TMH-1, refer- 


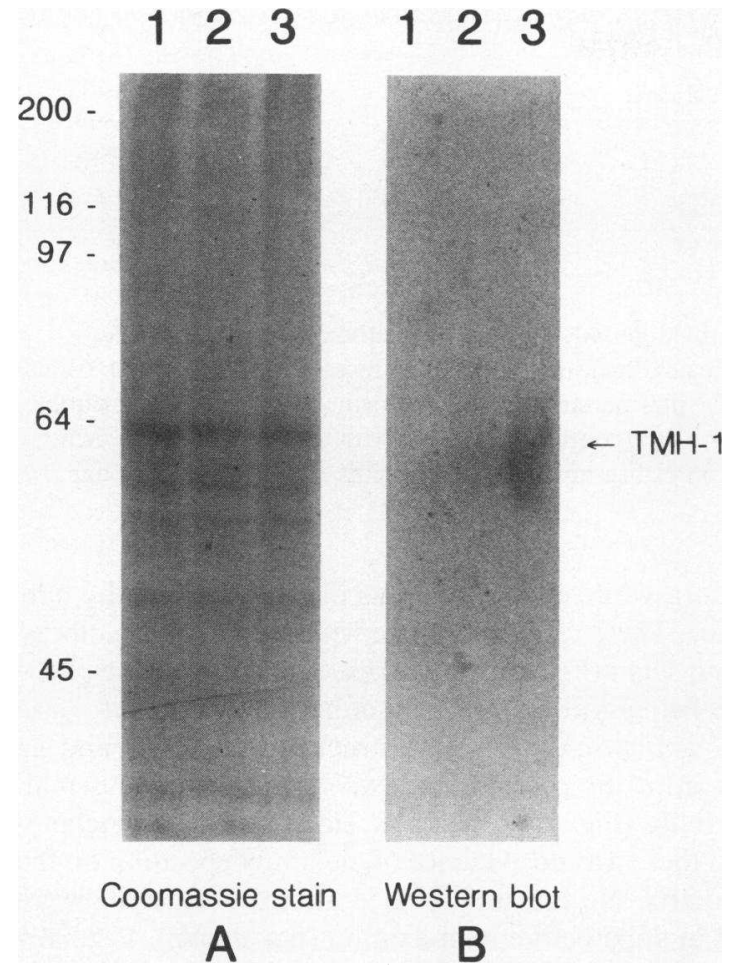

Figure 3. Immunoblot of hairbulb tyrosinase, using anti-tyrosinase monoclonal antibody TMH-1 (7). Lanes 1 and 3 are normally pigmented controls. Lane 2 is the proband. Molecular weight markers are indicated on the left of the figure. $(A)$ Coomassie stain. $(B)$ Antityrosinase antibody.

ence 7) demonstrated the presence of immunoactive enzyme in an extract of scalp anagen hairbulbs. As shown in Fig. 3, the extract of hairbulbs from the proband and from two normally pigmented controls contained a single immunoactive band that was $\sim 68 \mathrm{kD}$ in size, indicating that tyrosinase was present in hairbulbs that were visually producing no pigment. Furthermore, the amount of immunoactive tyrosinase in a 50-hairbulb sample from the proband did not appear to be abnormal be-

Table I. Hairbulb Tyrosinase (Tyrosine Hydroxylase) Activity: Assay at Different Temperatures

\begin{tabular}{lccc}
\hline Source & Hair sample & Assay temperature & Tyrosinase activity* \\
\hline \multirow{4}{*}{ Proband } & & ${ }^{\circ} \mathrm{C}$ & pmol/hb per $h$ \\
& Scalp & 22 & 0 \\
& & 25 & 0 \\
& & 30 & 0.05 \\
& & 35 & 0 \\
& & 37 & 0.06 \\
Control $^{\ddagger}$ & Leg & 43 & 0 \\
& Scalp & 37 & 0 \\
\hline
\end{tabular}

* Each value represents a mean of duplicate assays from a single 10hairbulb sample. ${ }^{\ddagger}$ Control hair color: brown.
Table II. Hairbulb Tyrosinase (Tyrosine Hydroxylase) Activity: Preincubation at Different Temperatures

\begin{tabular}{cccc}
\hline & \multicolumn{2}{c}{ Temperature } & \\
\cline { 2 - 3 } Source & Preincubation & Assay & Tyrosinase activity \\
\hline \multirow{3}{*}{ Proband } & ${ }^{\circ} \mathrm{C}$ & ${ }^{\circ} \mathrm{C}$ & pmol/hb per $h$ \\
& 25 & 37 & 0 \\
& 28 & 37 & 0.16 \\
& 30 & 37 & 0 \\
& 35 & 37 & 0 \\
Control $^{\ddagger}$ & 37 & 37 & 0.16 \\
& 25 & 37 & 0.21 \\
& 28 & 37 & 0.48 \\
& 30 & 37 & 0.41 \\
& 35 & 37 & 0.82 \\
& 37 & 37 & 0.66 \\
\hline
\end{tabular}

* Each assay was run in duplicate from a single 10-hairbulb sample.

^ Control hair color: brown

cause the blot was similar to that found in the 50-hairbulb extract from the controls, particularly the control in lane 1.

Quantitation of hairbulb tyrosinase activity. To determine if the unusual pattern of pigmentation resulted from a temperature sensitive enzyme, we first assayed hairbulb tyrosinase (tyrosine hydroxylase) activity at different temperatures of incubation. As shown in Table I, scalp anagen hairbulb extracts from the proband contained little or no detectable tyrosinase activity when the standard tritiated tyrosine assay (1) was carried out over a broad range of temperatures $\left(22-43^{\circ} \mathrm{C}\right)$, and a leg hairbulb extract had no activity when assayed at $37^{\circ} \mathrm{C}$. To determine if synthesis or processing of tyrosinase was temperature sensitive, we also assayed hairbulb tyrosinase (tyrosine hydroxylase) activity after an 18-h preincubation period at different temperatures. As shown in Table II, enzyme activity was present at low levels in scalp hairbulbs of the proband that were preincubated at 28 and $37^{\circ} \mathrm{C}$ and was undetectable in hairbulbs that were preincubated at other temperatures. These results suggested the presence of at least a small amount of active tyrosinase in the proband's hairbulbs, but failed to demonstrate a definite temperature effect on the function of the enzyme.

To more accurately characterize the small amount of tyrosinase activity present, we utilized an assay of the dopa oxidase activity of tyrosinase (6). This assay is more sensitive than the standard tritiated tyrosine assay, and provides better definition of the low end of the activity range. The results are given in Table III and Fig. 4. Scalp and leg hairbulbs from the proband were assayed at $22,25,30,35,37$, and $43^{\circ} \mathrm{C}$. Scalp hairbulbs from a normally pigmented individual with brown hair were assayed at $27,31,32,37$, and $43^{\circ} \mathrm{C}$ as a control. Because of the difference in total activity between the proband and the control, the results in Fig. 4 are expressed as percent of maximum activity. Tyrosinase activity in hairbulbs from the control individual increased at each higher temperature of incubation. In contrast, the tyrosinase activity from the scalp and the leg hairbulbs of the proband increased to $35-37^{\circ} \mathrm{C}$, but then decreased to $40 \%$ (scalp) and $65 \%$ (leg) of maximum activity at higher temperatures. These data demonstrate a temperature sensitive dopa oxidase activity of tyrosinase in the proband. 
Table III. Hairbulb Tyrosinase (Dopa Oxidase) Activity: Assay at Different Temperatures

\begin{tabular}{|c|c|c|c|}
\hline Source & Hair sample & Assay temperature & Tyrosinase activity* \\
\hline & & ${ }^{\circ} \mathrm{C}$ & pmol/hb per $h$ \\
\hline \multirow[t]{12}{*}{ Proband } & Scalp & 22 & 0.009 \\
\hline & & 25 & 0.023 \\
\hline & & 30 & 0.044 \\
\hline & & 35 & 0.068 \\
\hline & & 37 & 0.036 \\
\hline & & 43 & 0.027 \\
\hline & Leg & 22 & 0.016 \\
\hline & & 25 & 0.019 \\
\hline & & 30 & 0.030 \\
\hline & & 35 & 0.057 \\
\hline & & 37 & 0.082 \\
\hline & & 43 & 0.053 \\
\hline \multirow[t]{5}{*}{ Control $^{\ddagger}$} & Scalp & 27 & 0.308 \\
\hline & & 31 & 0.505 \\
\hline & & 33 & 0.649 \\
\hline & & 37 & 0.726 \\
\hline & & 43 & 0.760 \\
\hline
\end{tabular}

* Each value for the proband represents an assay from a single threehairbulb assay. Each value for the control represents a mean of duplicate three-hairbulb assays; the variation in the duplicate values was $\pm 8 \%$. ${ }^{\ddagger}$ Control hair color: brown.

Melanin biosynthetic pathway analysis. 5SCD is an precursor of pheomelanin and 5M6HICA is a methylated derivative of a precursor of eumelanin and the measurement of these two compounds can be used to estimate the activity of the two parts of the melanin pathway. As shown in Table IV, plasma 5SCD and urine 5M6HICA were detectable at low levels in the proband. This indicates that the melanocytes in the proband are capable of synthesizing both types of melanin.

Total pheomelanin and eumelanin in scalp, axillary, pubic, and leg hair from the proband and scalp hair from a control individual with brown hair were also determined, as shown in Table V. The amount of melanin was reduced in all hair samples from the proband; furthermore, all samples contained

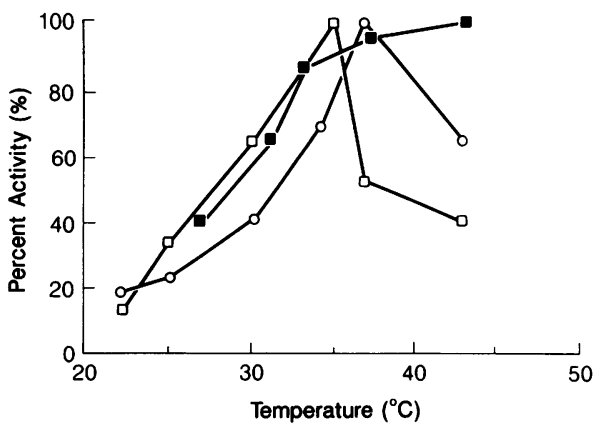

Figure 4. Dopa oxidase activity of hairbulb tyrosinase at different temperatures for the proband and a normally pigmented control individual with brown hair. Results are expressed as percent of maximum activity. (ロ) Normal control, scalp hairbulbs; ( $\square$ ) proband, scalp hairbulbs; (O) proband, leg hairbulbs.
Table IV. Melanin Pathway Intermediates

\begin{tabular}{ccc}
\hline & Plasma $5 \mathrm{SCD}^{*}$ & Urine $5 \mathrm{M} 6 \mathrm{HICA}^{\ddagger}$ \\
\hline$n g / m l$ & $\mu g / m l$ creatinine \\
Proband & $0.26 \pm 0.03^{\S}$ & $0.64^{\S}$ \\
Controls & $1.45 \pm 0.90^{\prime \prime}$ & $8.99 \pm 7.51^{\natural}$ \\
\hline
\end{tabular}

* 5-S-cysteinyldopa. Mean \pm SD. ${ }^{\ddagger}$ 5-Methoxy-6-hydroxyindole2-carboxylic acid measured in 24-h urine samples. Mean \pm SD. ${ }^{\S}$ Values from five plasma samples and one urine sample. "Plasma samples from six unrelated control individuals with brown hair. '24-h urine samples from eight unrelated control individuals with brown hair.

pheomelanin while eumelanin was present only in the hair from her leg. These results correlate with the observed color of the proband's hair (Fig. 2), and suggest that at least some pheomelanin is being synthesized in all of her melanocytes.

Electron microscopy. The ultrastructure of the scalp and leg hairbulbs from the proband, shown in Fig. 5, was normal. Scalp hairbulbs (Fig. $5 \mathrm{~A}$ ) contained stage I and II premelanosomes and there was no evidence of melanin deposition on the internal matrix. No melanin formed after the hairbulbs were incubated in dopa before final fixation (not shown). Leg hairbulbs (Fig. $5 \mathrm{~B}$ ) contained stage II and III premelanosomes and stage IV melanized melanosomes, in a pattern that is similar to scalp hair from a normally pigmented individual with brown hair.

\section{Discussion}

Oculocutaneous albinism (OCA) is a striking genetic abnormality characterized by congentially reduced pigmentation of the skin, hair, and eyes (14). At least three types are related to abnormalities of tyrosinase, the enzyme catalyzing the initial two steps in the melanin biosynthetic pathway: the hydroxylation of tyrosine to dopa and the dehydrogenation of dopa to dopaquinone (15). Type IA (tyrosinase negative) OCA is characterized by the total, life-long absence of melanin synthesis associated with a lack of demonstrable tyrosinase activity in all tissues of an affected individual $(1,14,16)$. In type IB (yellow) OCA the phenotype is similar to type IA at birth, but pheomelanin develops in the hair within the first few years of life, followed by eumelanin in the adult (2), suggesting that some residual tyrosinase activity remains in the melanocytes. In type

Table V. Hair Melanin Content

\begin{tabular}{ccc}
\hline Source & Eumelanin $^{*}$ & Pheomelanin* $^{*}$ \\
& $n g /$ mg hair & $n g / m g$ hair \\
Proband & & \\
Scalp & 0 & 8 \\
Axillary & 0 & 7 \\
Pubic & 0 & 9 \\
Leg & 140 & 10 \\
Control $^{\ddagger}$ & 335 & 15 \\
\hline
\end{tabular}

\footnotetext{
* Each value is the mean of two samples. ${ }^{\ddagger}$ Control hair color: brown.
} 

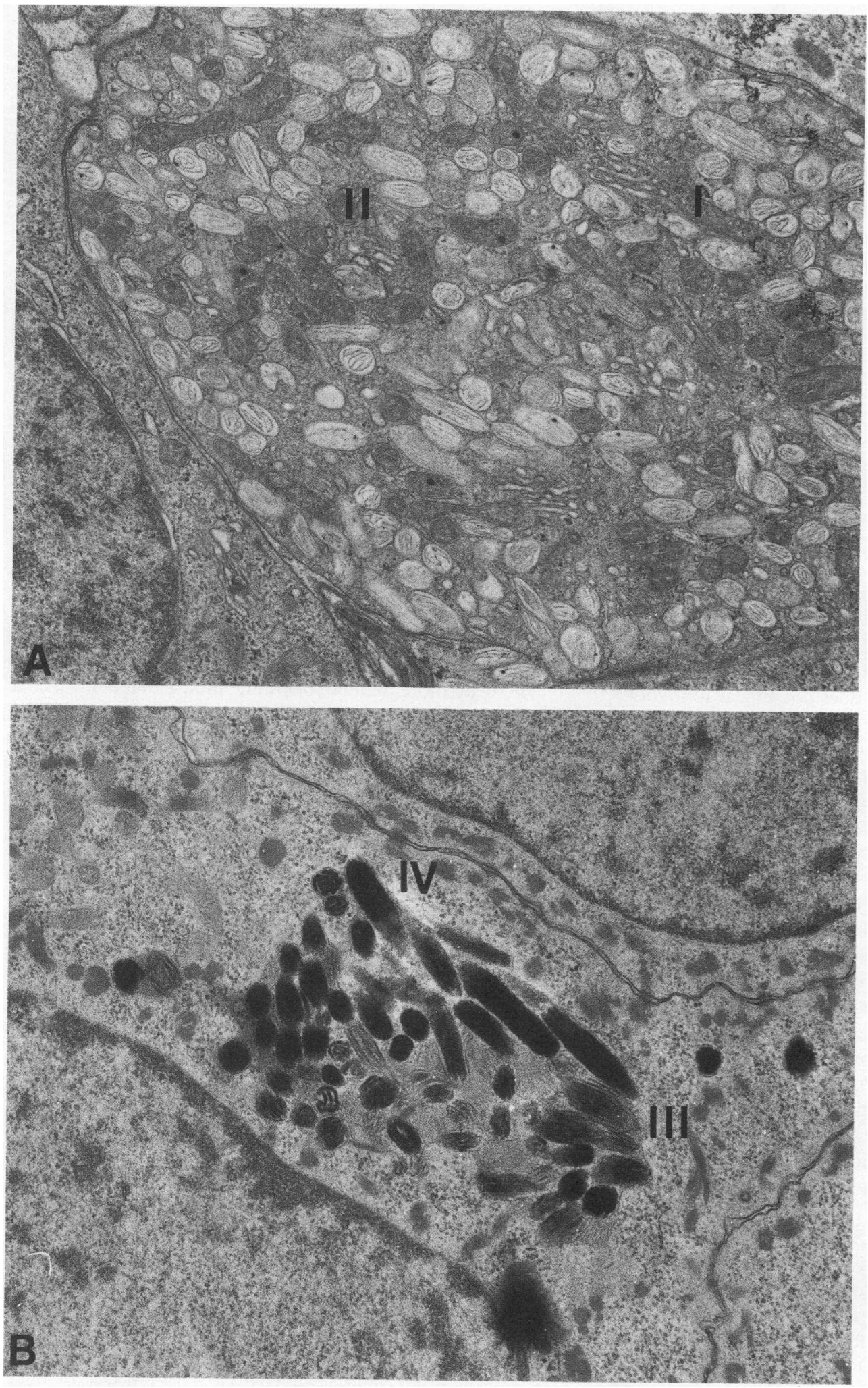

Figure 5. Electron microscopy of hairbulb melanocytes, without dopa incubation. $(A)$ Scalp hairbulb. (B) Leg hairbulb. I, II, and III indicate stage I, II, or III premelanosomes, and IV indicated stage IV melanized melanosome.

III (minimal pigment) OCA the phenotype is also similar to type IA early in life, but iris pigment develops in the first decade of life (4). Type IA and IB are thought to be allelic (3), but their relationship to type III is unknown. Affected individuals with all three types have reduced or absent hairbulb tyrosinase activity (1).
We now describe another interesting phenotype of tyrosinase-related OCA that is associated with deficient tyrosinase activity. The proband (individual II-4 in Fig. 1) appeared to have type IA OCA before puberty, with no evidence of skin, hair, or eye pigment. After puberty her arm and leg hair became pigmented (leg $>$ arm), whereas her scalp and axillary hair re- 
mained white. No iris or retinal pigment developed. This pattern of pigment distribution correlates with local body temperature, and is similar to that of the Siamese cat and the Himalayan rabbit, guinea-pig, and mouse $(17,18)$ in which tyrosinase enzymatic activity is thermosensitive. As shown in Table III and Fig. 4, tyrosinase extracted from the scalp and leg hairbulbs from the proband was sensitive to higher temperatures and exhibited greatly decreased activity at $35^{\circ} \mathrm{C}$ and above as compared to control enzyme when measured with the dopa oxidase assay. The temperature sensitivity was demonstrated with an assay for the dopa oxidase function of tyrosinase but not with the standard tritiated tyrosine assay that measures the tyrosine hydroxylase function of tyrosinase. The tyrosine hydroxylase assay is not sufficiently sensitive at low levels of enzyme activity, and gives inconsistent results in this range of activity. This is the first description of a human temperaturesensitive pigment mutation. Moreover, extensive studies of this family indicate that the proband is a genetic compound for this novel tyrosinase allele and a type IA allele (19). Therefore, the temperature-sensitive tyrosinase defect is apparently allelic to type IA OCA and most likely is the result of a mutation of the tyrosinase structural gene.

The specific biochemical mechanism for temperature sensitivity is unknown. The amount and electrophoretic position of immunoactive tyrosinase from the proband is similar to the normal glycosylated tyrosinase from control individuals (Fig. 3 ), indicating that the abnormality does not appear to involve enzyme processing or degradation. The normally pigmented melanosomes in the leg hairbulbs (Fig. 5) are additional evidence of normal packaging and processing of the enzyme in the melanocyte. Studies of the Himalayan mouse suggest several mechanisms that would produce a temperature-sensitive enzyme. Kidson and Fabian suggested that there may be an altered, temperature-sensitive affinity for a natural enzyme inhibitor, and found evidence for a low molecular weight inhibitor in homogenates of mouse skin (20). In contrast, Halaban et al. suggested that tyrosinase thermostability may be due to glycosylation of the enzyme, and demonstrated reduced glycosylation of Himalayan tyrosinase extracted from cultured dermal melanocytes (21). The tyrosinase gene of the Himalayan mouse has now been cloned and has been shown to contain an $A \rightarrow G$ substitution in codon 402 that results in a his $\rightarrow$ arg amino acid substitution in the peptide (22). The mutation does not occur in an area that is thought to be a potential glycosylation site (16), and site-directed mutagenesis and expression studies will be necessary to determine the precise mechanism for the change in thermostability with this mutation.

Some pigmentation of the hair, and less often of the skin, is found in most types of OCA, and the predominant hair pigment is pheomelanin (1). If eumelanin forms, it usually does so after pheomelanization. The apparent explanation of this phenomenon is related to the fate of dopaquinone, the product of the initial steps of the pathway. Dopaquinone combines rapidly with sulfhydryl compounds to form cysteinyldopas and eventually red-yellow pheomelanin (23). Alternatively, in the absence of sulfhydryl compounds, dopaquinone more slowly forms dopachrome that is enzymatically converted to indole compounds and the black-brown eumelanins (24). In most human pigmented tissue, both types of melanin are present as a mixture (23). The normal regulation of pheomelanin and eumelanin synthesis is poorly understood, but it is known that sulfhydryl compounds are normal constituents of the melanocyte $(25,26)$. Therefore, with abnormal tyrosinase function, less dopaquinone is formed and most is used for the synthesis of pheomelanin (1).

The quantitation of the pathway intermediates and hair melanin of the proband were consistent with the observed pigmentation of little or no melanin in the axillary and scalp hair, a predominance of pheomelanin in the arm hair, and dark eumelanin in the leg hair. The hair follicles in the scalp and axilla are the warmest, and a temperature-sensitive tyrosinase would be maximally inactivated in these regions, with little or no associated melanin synthesis. Skin temperature varies by location, with the highest temperature recorded for the scalp, axilla, chest, and abdomen, and lower temperatures for the extremities that decrease from proxymal to distal locations (27). The proxymal, mid, and distal temperatures of the arm are greater than those for the leg (27), and the basal enzyme activity should be lower in the arm hair follicles. As a result, less dopaquinone would be formed in the initial steps of melanin synthesis and most would preferentially be shunted into the higher-affinity pheomelanin pathway $(1,23)$. In the cooler hair follicles of the leg, less tyrosinase inactivation would result in greater eumelanin synthesis. The levels of cysteinyldopa ( $18 \%$ of control) and 5M6HICA (7\% of control) of the proband (Table IV) suggest that pheomelanin synthesis was more generally active than eumelanin synthesis in this individual.

There are more than 60 loci in the mouse that control coat color, but mutations at only one or two produce OCA (16). The $c$-locus in the mouse appears to represent the tyrosinase gene, and a series of $c$-locus alleles have been described that correlate with characteristic hypopigmented phenotypes, including the chinchilla, platinum, and Himalayan. A similar series of tyrosinase alleles appears to be present in human, including type IA, IB, and possibly minimal pigment OCA $(16,19)$. The phenotype described in this report apparently results from a novel allele that encodes a temperature-sensitive form of tyrosinase. Additional human tyrosinase alleles probably exist, resulting in different amounts of residual enzymatic activity and a wide variety of pigmentation phenotypes (28).

\section{Acknowledgments}

This work was supported in part by National Institutes of Health grant GM22167 and a grant from the Division of Research Resources General Clinical Research Center MO1RROO400.

\section{References}

1. King, R. A., and D. P. Olds. 1985. Hairbulb tyrosinase activity in oculocutaneous albinism: suggestions for pathway control and block location. Am. J. Med. Genet. 20:49-55.

2. Witkop, C. J., W. E. Nance, R. F. Rawls, and J. G. White. 1970. Autosomal recessive oculocutaneous albinism in man: evidence for genetic heterogeneity. Am. J. Hum. Genet. 22:55-74.

3. Hu, F., J. M. Hanifin, G. H. Prescott, and A. C. Tongue. 1980. Yellow mutant albinism: cytochemical, ultrastructural, and genetic characterization suggesting multiple allelism. Am. J. Hum. Genet. 32:387-395.

4. King, R. A., J. D. Wirtschafter, D. P. Olds, and J. Brumbaugh. 1986. Minimal pigment: a new type of oculocutaneous albinism. Clin. Genet. 29:42-50.

5. King, R. A., D. P. Olds, and D. W. Townsend. 1987. Mechanisms of hypopigmentation in human oculocutaneous albinism. In Advances in Pigment Cell Research. B. Bagnara, editor. Alan R. Liss, Inc., New York. 183-191.

6. Townsend, D. W., D. P. Olds, and R. A. King. 1986. Dopa oxidase activity in human hairbulbs measured by HPLC. J. Invest. Dermatol. 86:570-572.

7. Tomita, Y., P. M. Montague, and V. J. Hearing. 1985. Anti-tyrosinase monoclonal antibodies: specific markers for pigmented melanocytes. J. Invest. Dermatol. 85:426-430. 
8. Towbin, H., T. Staehelm, and J. Gordon. 1979. Electrophoretic transfer of proteins from polyacrylamide gels to nitrocellulose sheets: procedure and some applications. Proc. Natl. Acad. Sci. USA. 76:4350-4354.

9. Ito, S., T. Kato, K. Maruta, and K. Fujita. 1984. Determination of DOPA, dopamine, and 5-S-cysteinyl-DOPA in plasma, urine, and tissues by high-performance liquid chromatography with electrochemical detection. J. Chromatograph. 311:154-159.

10. Wakamatsu, K., S. Ito, and K. Fujita. 1988. Melanin-related metabolites in urine of B16 melanoma-bearing mice. Acta Dermatol. Venerol. 68:385-389.

11. Hansson, C. 1984. 6-Hydroxy-5-methoxyindole-2-carboxylic acid in normal human urine. Acta Dermatol. Venerol. 64:185-190.

12. Pavel, S., and W. Van der Slik. 1986. Analysis of eumelanin-related indolic compounds in urine by high-performance liquid chromatography with fluorimetric detection. J. Chromatograph. 375:392-398.

13. Ito, S., and K. Fujita. 1985. Microanalysis of eumelanin and pheomelanin in hair and melanoma by chemical degradation and liquid chromatography. Anal. Biochem. 144:527-536.

14. King, R. A., and C. G. Summers. 1988. Albinism. Dermatol. Clinics. 6:217-228.

15. Lerner, A. B., and T. B. Fitzpatrick. 1950. Biochemistry of melanin formation. Physiol. Rev. 30:91-126.

16. Spritz, R. A., K. Strunk, L. B. Giebel, and R. A. King. 1990. Detection of tyrosinase gene mutations in a patient with type IA oculocutaneous albinism. $N$. Engl. J. Med. 322:1724-1728.

17. Searle, A. G. 1968. Comparative Genetics of Coat Colour in Mammals. Academic Press, Inc., New York. 308 pp.

18. Silvers, W. K. 1972. The c (albino) series of alleles. In The Coat Colors of
Mice. A Model for Mammalian Gene Action and Interaction. Springer-Verlag, New York. 59-82.

19. Giebel, L. B., K. M. Strunk, R. A. King, J. M. Hanifin, and R. A. Spritz. 1990. A frequent tyrosinase gene mutation in classic, tyrosinase-negative (type IA) oculocutaneous albinism. Proc. Natl. Acad. Sci. USA. 87:3255-3258.

20. Kidson, S. H., and B. C. Fabian. 1981. The effect of temperature on tyrosinase activity in Himalayan mouse skin. J. Exp. Zool. 215:91-97.

21. Halaban, R., G. Moellmann, A. Tamura, B. S. Kwon, E. Kuklinska, S. H. Pomerantzs, and A. B. Lerner. 1988. Tyrosinases of murine melanocytes with mutations at the albino locus. Proc. Natl. Acad. Sci. USA. 85:7241-7245.

22. Kwon, B. S., R. Halaban, and C. Chintamaneni. 1989. Molecular basis of Himalayan mutation. Biochem. Biophys. Res. Commun. 161:252-260.

23. Prota, G. 1980. Recent advances in the chemistry of melanogenesis in mammals. J. Invest. Dermatol. 75:122-127.

24. Leonard, L. J., D. Townsend, and R. A. King. 1988. Function of dopachrome oxidoreductase and metal ions in dopachrome conversion. Biochemistry. 27:6156-6159.

25. Benedetto, J.-P., J.-P. Ortonne, C. Voulot, C. Khatchadourian, G. Prota, and J. Thivolet. 1981. Role of thiol compounds in mammalian melanin pigmentation. I. Reduced and oxidized glutathione J. Invest. Dermatol. 77:402-405.

26. Jara, J. R., P. Aroca, F. Solano, J. H. Martinez, and J. A. Lozano. 1988 The role of sulfhydryl compounds in mammalian melanogenesis: the effect of cysteine and glutathione upon tyrosinase and the intermediates of the pathway. Biochim. Biophys. Acta. 967:296-303.

27. Houdas, Y., and E. F. J. Ring. 1982. Human Body Temperature. Its Measurement and Regulation. Plenum Publishing Corp., New York. 238 pp.

28. Summers, C. G., D. Creel, D. Townsend, H. Y. Handoko, and R. A. King 1990. Variable expression of vision in siblings with albinism. Am. J. Med. Genet. In press. 